\title{
Safety Information under Neoliberalism: The Chilean Case
}

\author{
Rodrigo Finkelstein \\ School of Communication \\ Simon Fraser University
}

\begin{abstract}
This paper explores the production and supply of safety information under a neoliberal regime, where economic incentives and competition rather than regulations, supervision and enforcement, comprise the common sense to guarantee a safe workplace. Following a political economy of communication framework on the Chilean sector, this assessment unpacks the relationship between Workers' Compensation Boards' (WCBs) informational resources and their economic process of exchange within a neoliberal context. The purpose of this paper is to provide a well-grounded theoretical outline to analyse safety information, and to offer a glimpse of the particular kind of informational resources and goods produced by neoliberal WCBs. The following analysis discloses that WCBs are compelled to cede control over their symbolic content to the dynamics of the market place and the logic of profit maximization. Economic and competition imperatives trigger the production, on the one hand, of informational resources as distorted rates, and on the other, of informational goods as pro-corporate safety knowledge. Workers are cognitively misled and left physically and mentally unprotected at the worksite. This paper claims that due to a free market model, Chilean WCBs fail to protect workers' health and safety by producing and supplying distorted rates and corporate friendly knowledge.
\end{abstract}

Keywords: Neoliberalism, safety information, political economy, workers' compensation board, health communication, Chile

\section{Introduction}

In 2010 the international media coverage of the 33 Chilean miners trapped 700 meters underground failed to make sense of the context and causes of the accident. In line with their business of capturing and selling audience to advertisers, the mainstream media framed this tragic event as an epic saga of government leadership, human survival and the triumph of the will to live. They fell short to report and explain why critical information about the dangers and threatening working conditions of the mine that would have prevented the accident in the first place was not released in advance. The Government Commission Report timidly and vaguely recognized that Workers' Compensation Boards (WCBs) lack of the independence to communicate and inform of strict and detailed safety measures 
since in case of an unfavourable report they could lose the company as a client (Comisión Asesora Presidencial para la Seguridad en el Trabajo, 2010). This recognition suggests that private WCBs are reluctant to circulate information that would risk the economic relationship held up with their client companies. It hints that the distribution of symbolic resources to address working conditions, adequate equipment, machinery maintenance, safety regulations and risk prevention measures, may be influenced by the forces of the market place.

This paper aims to shed light on this communication breach by examining how WCBs produce and supply informational resources and goods to their client companies to prevent work-related injuries, diseases and fatalities. Following a political economy of communication framework on the Chilean WCBs sector, I explore the relationship between WCBs' informational resources and their economic process of exchange within a neoliberal context. Free of governmental 'impurities' —e.g., regulations, supervision and enforcement-the Chilean case provides a unique setting to explore how safety information is shaped by economic imperatives. It is particularly instructive insofar as being able to reveal how the power of the free market influences the production of safety informational goods and resources. This paper aims to (a) provide a well-grounded theoretical outline to analyse safety information, and to (b) offer a glimpse of the particular kind of safety informational resources and goods produced under neoliberalism.

\section{WCBs in Chile}

WCBs are agencies that manage health and safety at the workplace. These institutions aim to compensate and prevent work related injuries, diseases and fatalities. As a result of the high accident rates due to the industrial revolution, WCBs were first introduced in Germany in 1884 and then spread to the rest of Europe and North America in the early 1900's (Guinnane \& Streb, 2015). These agencies operate on the basis of a compulsory insurance mechanism in order to fairly allocate the costs across member corporations. However, rather than limiting the growth of accidents, this insurance system proved to be very effective in delivering financial compensation to injured workers in a formalized way (Guinnane \& Streb, 2015).

In Chile, these agencies appear in 1958. Due to a weak state apparatus, private WCBs emerge ahead of government policies and later on were granted permission to operate along with the state sponsored WCB (Dümmer, 1997). Being mandatory to join a WCB, corporations are free to choose among four nationwide participants: the public Instituto de Seguridad Laboral, and the private Instituto de Seguridad del Trabajo, Mutual de Seguridad and Asociación Chilena de Seguridad. These insurance agencies compete in the market place for clients. Their offer consists mainly of (a) full medical treatment, physical and occupational therapy for a successful return to work, (b) sick pay, financial compensation and pensions, and (c) prevention of labor accidents and professional diseases. By improving their safety indicators through better medical and prevention aid, WCBs compete to attract new customers and enlarge their market share.

\section{Neoliberal Safety: Economic Incentives and Competition for a Safer Workplace}


Chile bears a neoliberal political economic order since the 70's. This neoliberal regime was imposed via Pinochet's violent coup d'état backed by the United States (Harvey, 2005). By exploiting the Chilean population's state of shock, Milton Friedman advised Pinochet to impose a rapid transformation of the Chilean economy, what Klein (2007) dubbed a 'shock therapy'. Freed from the state, this economic project is characterized by (a) privatizations, (b) deregulations, (c) cuts in social spending, (d) free trade, and (d) corporate tax cuts (Klein, 2007). Under a neoliberal order, the state resigns of its productive, distributive and regulatory functions, while the economic logic of the free market is given full authority to organize every aspect of social life.

Although WCBs in Chile were implemented before Pinochet's neoliberal state, their private and deregulated traits have galvanized since then. The 'neoliberal experiment' that took place in Chile (Klein, 2007) had the power to severely weaken public institutions and at the same time reinforce those agencies like WCBs who adhered to free market principles. Thus, the neoliberal state was not a setback for the WCBs sector which relied mainly on private participants but on the contrary areat impulse. In this regard, the public WCB was not set aside. It was allowed to continue its operations in order to receive those uneconomical workers that private WCBs denied to provide service like house maids.

Chilean WCBs operate fluently and comfortable within a neoliberal state. These institutions embrace one of the main neoliberal mottos, the power of the free market to regulate the economic and social life. Under the assumption of the ability of the market to self-regulate, the WCBs' sector relies almost entirely on economic incentives to manage health and safety at the worksite. With almost no safety regulations, standards, guidelines, supervision and enforcement, companies are left to regulate themselves on the basis of economic stimuli. There are no more than 32 general labour safety and health norms and 331 inspectors nationwide to supervise more than 433.000 corporations (Comisión Asesora Presidencial para la Seguridad en el Trabajo, 2010). On the basis of an incremental premium in case of fatalities, injuries and diseases, companies are encouraged to engage in the improvement of working conditions, maintenance of machinery, provision of safety training and delivering of safety personnel equipment. Following a neoliberal reasoning, companies should effectively manage workers' health and safety in order to stall or diminish their financial contribution. In addition, another free market assumption is that injuries, diseases and fatalities would decline due to WCBs' competition for new clients. In this regard, competition would push WCBs to improve their research and technical operations in order to lower injury rates and thus increase their market share by offering cheaper premiums. To sum up, free market safety relies on the premise that the pursuit of economic gain naturally encourages companies to provide a safe worksite and WCBs to improve their services.

\section{WCBs' as an Information-Intensive Sector: Information for Economic Exchange}

A feature that few scholars are aware of is that WCBs comprise an information-intensive sector. This trait has been largely overlooked. Regarded as scientific and technical entities, these agencies concentrate the production and circulation of huge symbolic resources to protect workers against workrelated fatalities, injuries and diseases. WCBs play an essential role in organizing and circulating numbers, data, concepts and texts through which workers can interpret and respond to labor risks. 
Workers' health and safety at the worksite is thus highly dependent on the production and distribution of WCBs' symbolic resources such as risk data, accurate indicators, and above all, high-quality safety knowledge. Although this is not something hidden, the power of WCBs in shaping workers' consciousness by producing and circulating information is only known to insiders of this sector. In this regard, I claim that WCBs constitute a cognitive monopoly on health and safety.

In addition, WCBs process of economic exchange is an informational one. This constitutes one of the main if not the main blind spot of WCBs. Contrary to common sense, WCBs are not agencies that trade medical and preventive services but insurance companies whose main product are rates to measure labor health events in exchange for a monthly premium. WCBs' central operation is the transformation of work-related fatalities, injuries and diseases into informational resources - e.g., injury rate, fatality rate, working days lost, incapacity rate - for the purpose of economic exchange (Finkelstein, 2015). In this regard, I claim that rather than be seen as providers of medical and preventive aid WCBs must be considered in terms of their economic process of exchange, that is, institutions that exchange information in a business relationship. Therefore, WCBs' symbolic realm must be addressed within the logic of institutions whose economic process is driven by the dynamics between client companies and the collection, organization, production and exchange of informational resources. In addition, WCBs' symbolic sphere must also be analyzed in their complementary process of assisting client companies in the administration of rates through informational goods. WCBs produce and distribute safety knowledge in the form of informational goods - e.g., posters, fliers, brochures, handbooks, communication campaigns - to support their client companies in exerting control over rates and premiums. In consequence, the examination of WCBs' symbolic production has to be done by framing WCBs as an information-intensive sector whose main economic process of exchange includes the production of rates to swap them against a premium as well as informational goods to manage the aforementioned rates and thus exert control over the cost of the premium.

\section{How to Theoretically Approach WCBs' Information}

Being WCBs intensive-information companies whose main product are rates to be exchanged for a premium, I suggest that WCBs' informational resources and goods should be addressed in relation to what Garnham (1990) calls the second phase of cultural production. Under a second phase, culture and information as a superstructural phenomenon comes to an end and becomes to be part of material production (Garnham, 1990). Subordinated to the free movement of capital, information production and exchange begins to be defined by the logic of the market place - i.e., offer/ demand. This means that when looking at WCBs informational resources and goods we should not be looking at issues of ideological control. There is no need to deal with the content itself since under a second phase there is no necessary coincidence between the content of information and the ideas of the dominant class (Garnham, 1990). This approach is critical to avoid inaccurate results by addressing WCBs' symbolic content in ideological terms -i.e., owners' and managers' dominant ideas. To understand the main drivers of safety information it is necessary to put aside concepts of ownership and ideological domination as Garnham (2014) correctly suggests when analysing information businesses. As we shall see, the relationship between the economic and symbolic dimensions of WCBs is a complex one, not explicable in terms of conscious intent or conspiracy. 
Furthermore, information should be conceptualized not as a product but as a commodity, as Schiller (2007) correctly points out when dealing with information-intensive businesses. Borrowing from Marx's (1990) commodity definition, information as a commodity fulfills the purpose of being exchanged in the market place rather than serving as something useful per se. Its utility comes from what it can bring in exchange. It is a vehicle that serves exchange value within a business relationship. In this regard, one of the main problems when analyzing this sector is taking for granted that the production of informational resources - e.g., injury rate, fatality rate, working days lost - is led by use value rather than exchange value. Informational resources are mistakenly taken as a measure of labor risks - i.e., as use value - rather than an informational commodity manufactured through a complex process of production to swap labor risks against a premium - i.e., as an exchange value (Finkelstein, 2015). This is highly problematic, because it obscures the fact that informational resources as commodities are removed from their capacity to work as an indicator and accurately reflect labor hazards at the worksite. Thus, it is vital to approach WCBs' informational resources as the result of commodification practices through which they are brought to life.

\section{Safety Information under Neoliberal WCBs}

Now that the economic, political and theoretical dimensions have been well established, it is possible to delve into the symbolic realm. In the lines that follow an overview of the particular kind of informational resources and goods produced by neoliberal WCBs is presented, analysed and discussed. Following a political economic framework, safety information is not presented as an autonomous phenomenon but in relation to the economic, political and social spheres. In addition, rather than something neutral and innocuous, safety information is displayed in the light of conflicting interests, power relationships and ethical concerns.

\subsection{Safety Informational Resources as Distorted Rates}

WCBs' main activity consists of the production of informational commodities for the purpose of economic exchange under free market conditions. These institutions transform tragic labor events into an informational commodity - rates - in exchange for a monthly premium (Finkelstein, 2015). Through the commodification of rates, WCBs are enabled to carry out the economic trade. The process of commodification, known as the transformation of use value into exchange value (Mosco, 2009) allows WCBs to price labor risks and set the premium. Safety informational resources - rates - are removed from their use value, transformed from ends to means, collected, sorted, classified and processed for the purpose of setting up the premium and allowing the trade. As any ordinary commodity, safety rates are promoted, advertized, packaged into products and commercialized by WCBs to attract new customers and enlarge their market share. In this regard, very similar to Smythe's (1981) concept of predictable specifications, these informational resources fall in economic sector classes - forestry, building, services, fishery, etc... - and diverse technical taxonomies enabling a price differentiation according to each companies' economic activity, historical performance 
and type of accident or disease. But as a collection of a diverse set of specifications these informational resources are commodities, since as a whole they can be transformed and reduced - by a complex mathematical equation — just to one rate to swap it against the premium.

Since rates are produced for the purpose of economic exchange, WCBs and corporations place their focus primarily on rates therefore engaging in somehow altering them. Both WCBs and corporations are stimulated to intervene in some stages of the process of production in an attempt to manipulate rates in their own favour. For example, corporations tend to misinform, discourage, and even threaten workers to prevent them from reporting labor injuries and diseases. These simple practices enable corporations to hamper a surge in rates thus holding the premium back. On their part, WCBs tend to ignore them to avoid disputes, keep intact their market share, and attract new clients through the commercial incentive of low rates. Rather than having a small gain due to an increase on premiums WCBs prioritize on preserving clients and therefore respond in an indulgent way. However, WCBs do not take a passive position to prevent the rise of rates. They also place pressure on some stages of the process that are under their influence to uphold rates for keeping clients satisfied and preserving their commercial hook. WCBs push for 'express medical services' (Finkelstein, 2009) - i.e., quick medical assistance - to minimize the working days lost and protect their client companies from a premium increase. Moreover, WCBs short rates through the bureaucratic practice of re-classifying data. Through conceptualizing and classifying treatment days as 'postponements' or 'deferrals' WCBs prevent treatment days from being counted as lost days thereby maintaining the working days lost rate and preventing a premium surge. Due to its subtleness, re-classifying data is extremely difficult to denounce since it is executed under administrative and technical procedures.

As seen, the commodity nature of rates has serious implications for the kind of information produced. It plays a key role in producing safety misinformation in the form of distorted rates. With this regard, as misinformation takes place as a result of the commodity form of rates, misinformation can be understood as a reflection of WCBs' process of production and exchange. This happens because rates as commodities allow the forces of economic calculation to enter the stage and indirectly and unintentionally create distortions. Since WCBs and companies are economically pushed to routinely alter the process of production of rates in an attempt to control them to their own economic benefit, safety misinformation and misperception are brought into existence. Distorted rates are the outcome of WCBs' process of production and neoliberal context. It is the very nature of WCBs' economic model characterized by its reliance on the free market that makes WCBs to resign from their responsibility in providing accurate rates. WCBs failure to serve the public interest by producing and circulating distorted rates is not explicable in terms of conspiracy but by the commodification of rates through which WCBs are economically organized.

\subsection{Safety Informational Goods as Corporate Friendly}

As part of its economic process WCBs produce and distribute safety knowledge in the form of informational goods - e.g., posters, fliers, brochures, handbooks, merchandising - to support their client companies in managing rates - i.e., keep rates stall or reduce them. Although informational goods are not exchanged for a premium, as the case with rates mentioned above, they are nevertheless 
under economic pressure to operate according to the dictates of the market place rather than workers' health and safety. Safety informational goods as safety packaged knowledge - e.g., posters, fliers, brochures, handbooks - operate as a commodity since they are conditioned by an exchange value relationship.

In this regard, since WCBs target corporations as clients, WCBs tend to produce and circulate corporate-friendly informational goods. As far as the clients are companies rather than workers, the symbolic production must fulfill corporate needs. By producing, packaging, marketing and advertising safety knowledge amenable to companies, WCBs compete against each other to keep and increase their customer base. The free market value of satisfying the client shapes to a great extent the nature of the symbolic content produced and dispersed as knowledge by WCBs. It is therefore WCBs' free market design which explains the production and circulation of pro-corporate perspectives on labor health and safety. WCBs present safety as synonymous with business interests - e.g., productivity, efficiency, loss control management - and as workers' responsibility - e.g., unsafe actions, unsafe attitudes, failure to use personal protective equipment. These corporate-friendly meanings are framed by WCBs as scientific knowledge therefore producing corporate ideology. Due to workers' vital need to attribute meaning to events (Geertz, 1973), especially significant events like labor injuries and diseases, WCBs are in a powerful position to advance pro-corporate hegemonies without being contested. These institutions exploit workers' vital need to make sense of fatalities, injuries and diseases by providing hegemonic views that work against their own interests.

As a result of the free market pressure, WCBs' informational goods on how to prevent workrelated accidents and diseases take the form of a dominant perspective through which workers are brought into consent. WCBs' institutional knowledge becomes an hegemony, a taken for granted and unchallenged view that drives consensus over the adequate and acceptable ways of managing labor hazards. This safety hegemony carries with it mental and institutional tools that shape classifications, perceptions and interpretation schemes on which strategies, actions and policies are aligned. Also, it does eliminate alternative views on how to manage labor health and safety thus restraining the range of concepts and messages and limiting the repertoire of safety informational goods. In consequence, contrary to the presumed benefits of a free market scheme where competition results in the natural expansion of the offer, the repertoire of symbolic resources gets halted by WCBs' client orientation. In this case, the free market value of satisfying the client results in a homogenization of safety informational goods.

Pro-corporate safety perspectives are characterized foremost by an unequal distribution of the blame. The responsibility for an accident is removed from the social organization of the work something that the corporation is responsible for - and placed on workers themselves. For example, based on a well-known claim from H.W. Heinrich that $88 \%$ of labor accidents are due to unsafe acts performed by workers (Heinrich, 1931), pro-corporate discourse can successfully relocate the blame of labor accidents and diseases on the individual. It doesn't matter that Heinrich's study had serious methodological faults in terms of how data was collected, the quality of the data, the analysis method and the evidence of his conclusions (Manuele, 2011). As far as Heinrich's conclusions provide the adequate rationale to support companies in relocating the blame, this pseudo-knowledge is incorporated in informational good, circulated, promoted and advertised as scientific knowledge by WCBs. 
Also, by following Loss Control Management (Bird \& Loftus, 1976), WCBs support companies' interests by framing safety as an economic practice. WCBs promote Bird \& Loftus' logic of reducing accidents by decreasing property loss, property damage and productive delays. Under this perspective, labor accidents are redefined as 'incidents' in order to equalize them to property loss and damage incidents and therefore blend them together under a productive chain of management control. This allows companies to control labor accidents and diseases in line with their production processes by deleting the natural conflict between safety and productivity.

WCBs know that in order to succeed in the market place it is not enough to produce and circulate informational goods amenable to companies but to extensively promote and marketize this view. In this regard, WCBs engage in propaganda favourable to corporate interests in order to build their brand around a pro-corporate appeal and imbue themselves with an attractive business image. On a regular basis WCBs promote through the mass media what they call a 'safety culture', a series of corporate messages directed to the general public on how to achieve health and safety at the worksite. This 'safety culture' propaganda is saturated with pro-corporate meanings and anti-workers' myths - e.g., workers as unsafe, ignorant and lazy. Mainly, these messages reinforce both the displacement of accidents' responsibility -from the organization to workers- and the economic perspective of safety. On the one side, by promoting safe attitudes, safety behaviours, the use of personal protective equipment and complying with the organization's rules, WCBs install the hegemony that accidents are due to workers' fault rather than companies' social organization of work. On the other side, by linking safety to productivity, efficiency, property damage, savings and a good corporate image, WCBs establish the hegemonic view that safety is as an economic activity to be pursued in line with companies' economic interests. In this regard, the strongest hegemony promoted by WCBs is the idea that corporate and workers' values, interests and priorities are one and the same. By constantly meshing corporate interests and workers' needs, WCBs create the notion that by promoting workers' health, companies' interests can be achieved and vice-versa. This hegemony enables WCBs to occlude the natural conflict between corporate interests and workers' health, an issue that prominent health scholars call to address (Karassek \& Theorell, 1990; Siegrist, 1996).

\section{Concluding Remarks}

This examination shows that WCBs' informational resources and goods are strongly intertwined to their economic process of exchange and neoliberal regime. WCBs are compelled to cede control over their informational resources and goods to the dynamics of the market place and the logic of profit maximization. Both the free market and WCBs' process of exchange constitute the key reference point to make sense of the production of safety information. On the one side, due to the commodification of informational resources - i.e., rates - and the economic incentive to keep them down both by WCBs and their client companies, distorted informational resources are inadvertently created and dispersed. On the other side, due to WCBs' need to direct the production and promotion of informational goods to their client companies, pro-corporate perspectives on safety are involuntarily brought to life as an all-encompassing hegemony. By ceding control over their symbolic content to the dynamics of the market place and the economic logic, WCBs also cede their social responsibility to provide accurate informational resources and goods to protect workers at the workplace. Chilean 
WCBs fail to protect workers against labor hazards by producing and supplying distorted informational resources and pro-corporate informational goods.

The effects of distorted rates and pro-corporate views are not negative to everyone as it might appear. The impact is a dialectic one, with workers as losers on the one side and WCBs and corporations as winners on the other. Since workers rely on WCBs for accurate risks information and high quality safety knowledge to interpret and respond to labor hazards, the production and circulation of distorted and corporate friendly information harms them directly. Workers are cognitively misled and left physically and mentally unprotected at the worksite. On the one hand, distorted low rates minimize the degree of risks at the worksite, and on the other, pro-corporate safety knowledge occludes the risks of the social organization of work. Social dimensions of health such as excessive demand, low control, effort/reward imbalance and lack of social support (Wilkinson, 2001) are completely neglected and left apart. Safety misperception as an inaccurate mode of perceiving hazards at the worksite arises as the main outcome of the lack of accurate informational resources and goods. Regarding WCBs and their client corporations, the production of distorted and pro-corporate information is convenient for both of them. First, distorted rates allow WCBs and companies to maintain a supportive public opinion. Low rates bring legitimacy to WCBs by presenting them as thriving institutions and give prominence to companies by presenting them as socially responsible. Second, corporate friendly knowledge aid WCBs and companies to sustain policies hurtful to corporate interests. Since pro-corporate safety knowledge liberates companies from their responsibility in the production of fatalities, injuries and diseases by relocating the blame on workers, companies are shielded from major interventions.

To conclude, it is important to emphasize that this communication breach is not because the right to high-quality information and knowledge is absent from the political scenario. Government officials are well aware that accurate safety information is vital to protect workers. The dilemma is that the right to high-quality safety information is placed in subordination to other rights. As Marx precisely stated, human rights are denied when rights of private property, capital accumulation and market exchange are given primacy (Marx, 1978). In this case, it is WCBs' primacy over market exchange, competition, and economic interests that indirectly deny the production and supply of accurate rates and safety knowledge. The refusal to high-quality safety information is a result of WCBs' economic organization. Therefore, it is imperative to transform WCB's economic base to allow the production and distribution of safety information in conditions of equity and liberty, in accordance to workers' non-commercial needs.

\section{Acknowledgement}

Thank you to the reviewers for valuable suggestions on this paper. This research was supported by a Student Graduate Stipend Award from the Centre for Research on Work Disability Policy (Social Sciences and Humanities Research Council Award 895-2012-1017). I am grateful to John Calvert for nominating me for this award. 


\section{References}

Bird, F., \& Loftus, R. (1976). Loss control management. Georgia: Institute Press.

Comisión Asesora Presidencial para la Seguridad en el Trabajo. (2010). Informe final. Retrieved from http://docplayer.es/348051-Comision-asesora-presidencial-para-la-seguridad-en-el-trabajo-informe-final.html

Dümmer, W. (1997). Occupational health and workman's compensation in Chile. Applied Occupational and Environmental Hygiene. 12 (12), 805-812.

Finkelstein, R. (2009). El rol constitutivo de la seguridad ocupacional. Ciencia \& trabajo, 33 (11), 145-151.

Finkelstein, R. (2015). The commodity form of safety information. Triple $C, 13(2), 610-623$. Retrieved from http://www.triple-c.at/index.php/tripleC/article/view/712/768

Garnham, N. (1990). Capitalism and communication: Global culture and the economics of information. London: Sage Publications.

Garnham, N. (2014). The political economy of communication revisited. In J. Wasko, G. Murdock and H. Sousa (Eds.). The handbook of political economy of communications. Oxford: John Wiley.

Geertz, C. (1973). The interpretation of cultures. New York: Basic

Guinnane, T. \& Streb, J. (2015). Incentives that (could have) saved lives: Government regulation of accident insurance associations in Germany, 1884-1914. The Journal of Economic History, 75(4), $1196-1227$.

Harvey, D. (2005). A brief history of neoliberalism. New York: Oxford University Press.

Heinrich, H.W. (1931). Industrial accident prevention: A scientific approach. New York: McGraw-Hill.

Karasek, R. \& Theorell, T. (1990). Healthy work: Stress, productivity, and the reconstruction of working life. New York: Basic Books.

Klein, N. (2007). The shock doctrine: The rise of disaster capitalism. New York: Metropolitan Books.

Manuele, F. A. (2011). Reviewing Heinrich: Dislodging two myths from the practice of safety. Professional Safety, October 52-61.

Marx, K. (1978). Economic and philosophic manuscripts of 1844. In R. Tucker (Ed.), The Marx-Engels reader (2nd ed.) (pp. 66-105). New York: W. W. Norton \& Company.

Marx, K. (1990). Capital, volume I. London: Penguin Classics.

Mosco, V. (2009). The political economy of communication (2nded.). London: Sage.

Schiller, D. (2007). How to think about information. Illinois: University of Illinois Press.

Siegrist, J. (1996). Adverse Health effects of high-effort/low-reward conditions. Journal of Occupational Health Psychology. 1(1), 27-41.

Smythe, D. (1981). On the audience commodity and its work. In M. Durham and D. Kellner (Eds.), Media and cultural studies: Key works (2nd ed.) (pp. 185-204). West Sussex, UK: Wiley-Blackwell.

Wilkinson, C. (2001). Fundamentals of health at work: The social dimensions. London: Taylor \& Francis. 